\title{
Educar pela pesquisa: as resistências sinalizando o processo de profissionalização de professores
}

\section{Educating through research: resistances as possibilities for the evolution of teachers' personal classroom theories}

\author{
Maria do Carmo Galiazzi* \\ Roque Moraes** $^{*}$ \\ Maurivan Güntzel Ramos***
}

\begin{abstract}
RESUMO
A partir de uma proposta de educação pela pesquisa em sala de aula, apresentamos três categorias de resistências que podem surgir ao fazer da pesquisa proposta metodológica em cursos de formação de professores: a inércia tradicional, a restrição ao diálogo, e as teorias de ensino, de aprendizagem e de avaliação. Propomos aos professores formadores estarem atentos às resistências em suas aulas, porque elas sinalizam para a superação das teorias de todos os envolvidos, possibilitando intervir de modo consciente e crítico no encaminhamento do processo de profissionalização dos futuros professores.
\end{abstract}

Palavras-chave: formação de professores; educar pela pesquisa, resistências, apropriações.

* Doutora em Educação. Professora do Mestrado em Educação Ambiental da Fundação da Universidade Federal do Rio Grande. E-mail: carmo@mikrus.com.br

** Doutor em Educação. Professor do Programa de Pós-Graduação em Educação da Pontifícia Universidade Católica do Rio Grande do Sul. E-mail: searom@pucrs.br

**** Doutor em Educação. Professor do Programa de Pós-Graduação em Educação da Pontifícia Universidade Católica do Rio Grande do Sul. E-mail: mgramos@pucrs.br 


\begin{abstract}
Starting from a proposal based on educating through research, we present three cathegories of resistance that may emerge when assuming the research as a methodological approach in teacher education courses: the traditional inertia, the restrictive dialog and the understandings of teaching, learning and evaluation. From this we insist that teacher educators be attentive to the resistances in their classes because they signal to the overcoming of the theories of the involved, allowing conscious and critical interventions in the conduction of professionalization of the future teachers.

Key-words: teacher education, dialogic inquiry, resistances, appropriations.
\end{abstract}

\title{
Introdução
}

A idéia de educar pela pesquisa não é nova. Diferentes autores a vêm aprofundando, entre eles DEMO (1998, 1997, 1996, 1995, 1991), PORLÁN e RIVERO (1998), CAÑAL (1999, 1997), GARCÍA (1998, 1997). No entanto, a idéia permanece inovadora porque são poucos os professores que a desenvolvem em aula, quer a partir do uso de resultados da pesquisa educacional ou como princípio articulador do currículo e da construção do conhecimento profissional do professor, a pesquisa em aula.

Discutimos neste texto a pesquisa em sala de aula com os alunos, pois entendemos que ela contribui de forma efetiva para a melhoria da formação de professores. No entanto, como ainda é uma idéia inovadora nos ambientes escolares, gera um movimento, geralmente implícito, de resistências.

$\mathrm{O}$ argumento que pretendemos desenvolver ao longo do texto é que o professor precisa estar atento a essas resistências, porque elas evidenciam as teorias pessoais dos participantes da pesquisa, quer sejam os alunos, quer seja o professor. Muitas vezes, ao perceber um determinado modo de resistência, o professor se dá conta da teoria pedagógica que sustenta aquela ação. Do mesmo modo, o professor precisa estar aberto à análise das resistências, pois essas resistências podem igualmente evidenciar suas próprias teorias, expressas nas ações dos alunos.

Quando a pesquisa é assumida como princípio educativo (DEMO, 1997), encontra nos professores, nos alunos e no contexto escolar alguns limites e 
resistências em função de um ensino tradicional ainda dominante. O termo resistência vai ser usado na abordagem proposta por WERTSCH (1998), em que, trazendo os aportes de Bakhtin e de De Certeau, esse autor considera que a apropriação de um significado novo sempre envolve algum grau de resistência. Segundo o autor, algumas formas de resistência são mais regra do que exceção. Em algumas situações a resistência é consciente; em outras o processo de apropriação do novo significado resulta em mudanças pouco perceptíveis que produzem ações irrefletidas. As resistências podem se manifestar mesmo com os indivíduos tendo a intenção de assumir um novo discurso, o que resulta em apropriações de significados em níveis diferenciados.

No caso específico da aula, a apropriação parece não ser algo sempre decidido pelos participantes. Parece derivar, principalmente, de um processo irrefletido a partir das práticas nas quais os alunos se engajam porque desempenham um papel específico. Ao invés de envolver reflexão consciente, ser uma ação de um agente e resultar em construção própria de significados, a aprendizagem geralmente está sujeita a uma dinâmica complexa de tensões permanentes entre resistências e apropriações de significados.

Os argumentos que estamos apresentando foram construídos a partir do resultado de pesquisa com quatorze professores, os quais têm por princípio a pesquisa em sala de aula, em cinco experiências diferenciadas de sala de aula, em cursos de formação de professores da área de Ciências. As entrevistas dos professores foram trianguladas com informações de quarenta e cinco alunos desses professores. As experiências de sala de aula foram acompanhadas durante um semestre (duas delas); dois semestres (duas delas); quatro semestres (uma delas).

O presente texto discute, inicialmente, as características das perspectivas tradicionais e investigativas que fazem parte do processo de formação de professores. A seguir apresenta de forma sintética a proposta de planejamento da sala de aula do educar pela pesquisa como desenvolvida por GALIAZZI (2000). A partir da análise de salas de aula do educar pela pesquisa, são discutidos três diferentes tipos de resistências que sinalizam para limites dos conhecimentos dos envolvidos. São essas resistências que possibilitam a problematização das teorias pedagógicas, geralmente tradicionais, de professores e alunos e que podem levar ao enriquecimento do conhecimento profissional do grupo. 


\section{As teorias pedagógicas e o educar pela pesquisa}

As perspectivas pedagógicas subjacentes à formação de professores vêm sendo estudadas há muito tempo. A intenção aqui é apresentar algumas características de duas dessas perspectivas apenas: a perspectiva tradicional e a perspectiva investigativa. A primeira, por ainda ser hegemônica em aula; a segunda, por incluir os princípios do educar pela pesquisa, fundamento teórico do presente texto.

PORLÁN e RIVERO (1998) apresentam três modelos pedagógicos nos professores: centrados no saber acadêmico, no saber técnico e no saber fenomenológico. Propõem um modelo de formação prático, em que o diálogo sustenta e é sustentado pela prática e cuja evolução ocorre pela investigação.

Concordamos com os autores, quando afirmam que a visão tradicional de formação apresenta um reducionismo epistemológico academicista por considerar como importantes apenas os conhecimentos disciplinares acadêmicos, tanto das disciplinas específicas como das disciplinas das Ciências da Educação. Essa visão, a par de considerar que o conhecimento profissional se constrói pela justaposição de conteúdos disciplinares acadêmicos, estabelece uma relação mecânica entre teoria e prática que resulta em uma transmissão dos conteúdos trabalhados na academia, desconectados dos conhecimentos trabalhados nas disciplinas pedagógicas.

De outra parte, considerando os enfoques investigativos da formação, PÉREZ-GÓMEZ (1998) os insere na perspectiva de "reflexão na prática para a reconstrução social". Nessa perspectiva estão as propostas de um ensino crítico pautado pela ética em que as intenções das ações orientam os processos de ensino e de aprendizagem. Esse autor diferencia as propostas em dois enfoques: o enfoque de "crítica e reconstrução social", com propostas didáticas concretas de justiça, igualdade e emancipação social, em que o processo de formação pretende desenvolver a consciência dos cidadãos para uma sociedade mais justa e igualitária. A escola precisa dar prioridade à capacidade de pensar criticamente, e o professor é considerado um intelectual transformador: educador e ativista político. Segundo o autor, Zeichner e Kemmis se inserem nessa perspectiva, e, apesar de sua importância, são poucos os exemplos de aplicação prática em vigor.

O segundo enfoque é a "investigação-ação" e teve seus primórdios na Inglaterra, na década de 60. Seus principais representantes são Stenhouse, MacDonald, Elliot e Schön. Para o primeiro, o ensino era como uma arte em que as idéias precisavam ser experimentadas na prática, de maneira reflexiva 
e crítica. Não poderia haver desenvolvimento curricular sem a formação docente pela pesquisa sistemática sobre a prática. Para Elliot, no entanto, a investigação surge como possibilidade mais de melhorar a prática do que de produzir conhecimento. Pela investigação, o professor transforma o cenário da aprendizagem de forma a capacitar os alunos a desenvolverem suas próprias capacidades. O professor não é um indivíduo isolado, e a reflexão sobre os processos complexos da aula requer diálogo, contraste, debate e enriquecimento com teorias e experiências alheias em coletivos. As escolas se transformam em centros de desenvolvimento profissional.

As idéias de Schön corroboram as idéias dos autores citados, sendo, inclusive, derivadas deles, principalmente em relação aos aspectos da reflexão na ação (o refletir do professor sobre a sua prática) e reflexão sobre a reflexão na ação (a pesquisa sobre a sua ação docente).

Esse autor apresenta três diferentes conceitos que integram o pensamento prático, associados à reflexão. $\mathrm{O}$ conhecimento na ação - que tem o sentido de conhecimento técnico ou solução de problemas, para Habermas está relacionado ao conhecimento implícito associado ao saber fazer. A reflexão na ação - ou deliberação prática, para Habermas - consiste em pensar sobre o que fazemos ao mesmo tempo em que atuamos. A reflexão na ação gera um metaconhecimento na ação, pois possui uma função crítica, colocando em questão a estrutura de suposição do conhecimento na ação e possibilitando a experimentação in situ, como afirma SCHÖN (1983), fazendo-nos pensar mais além e construindo mudanças, em geral, criativamente. A reflexão sobre a ação e sobre a reflexão na ação - reflexão crítica, para Habermas consiste, para Schön, na análise que é feita a posteriori sobre as características e os processos da própria ação. O conhecimento gerado nessa reflexão pode contribuir direta ou indiretamente para constituir nosso conhecimento e para modelar nossa ação futura.

O enfoque investigativo de formação também é analisado em PORLÁN e RIVERO (1998), que apontam a possibilidade de construção de um conhecimento profissional mais complexo pela inserção da pesquisa como recurso do formador que pesquisa os modelos didáticos dos futuros professores e, pela discussão e contrastação, possibilita sua evolução para modelos mais complexos. O modelo didático de referência é o que inclui a pesquisa do formador tecendo as relações de aula.

O educar pela pesquisa, que entendemos inserir-se no enfoque investigativo, inclui a pesquisa do professor sobre sua sala de aula, mas este texto discute a pesquisa como princípio metodológico em aula, com os alunos constituindo um grupo que pesquisa. 
No educar pela pesquisa (DEMO, 1998; 1997; 1996; 1995; 1991), a investigação se faz como princípio científico e como princípio educativo. Essa proposta se sustenta na pesquisa como princípio científico porque contribui para a construção de conhecimento, e como princípio educativo porque promove o questionamento crítico e inovador. Tem por objetivo desenvolver habilidades “indispensáveis em cada cidadão e trabalhador modernos: aprender a aprender e saber pensar para intervir de modo inovador" (DEMO, 1997, p. 9). A pesquisa é condição básica "por seu lado educativo emancipatório, sua marca de atitude cotidiana, sua viabilidade em qualquer pessoa, sua relação intrínseca com o conhecimento inovador" (DEMO, 1997, p. 53).

Concordamos com o autor que fazer pesquisa consiste em ler criticamente a realidade e, com compromisso político, contribuir para sua reconstrução de modo mais justo, com oportunidades mais equalizadas. Fazer pesquisa significa também reconstruir processos e produtos específicos da aula, sendo exemplos de atitudes de pesquisa a construção de proposta pedagógica própria, a construção de materiais didáticos, o exercício de escrita com argumentos claros e fundamentados, entre outros (DEMO, 1995).

$\mathrm{O}$ educar pela pesquisa agrega à componente da pesquisa feita pelo professor a que é desenvolvida em aula com os alunos. Nesse caso, é imprescindível assumir a aula como espaço coletivo de trabalho, em que professor e alunos são considerados parceiros de trabalho. $\mathrm{O}$ expediente mais estratégico nessa proposta está na qualidade construtiva do professor que busca proporcionar o questionamento crítico e criativo, procura desenvolver nos alunos a capacidade de comunicar por meio da construção de argumentos e contra-argumentos cada vez mais elaborados.

Ao ressaltar a importância da leitura, da construção do argumento, do desenvolvimento da capacidade de argumentação, educar pela pesquisa exige um discurso competente. Baseia-se em discursos abertos, rigorosos, sempre passíveis de questionamento. A discutibilidade é o critério principal da cientificidade. A coerência crítica adotada pelo professor precisa encontrar na autocrítica e na contracrítica sua maior autenticidade (DEMO, 1995).

É discurso competente "aquele devidamente argumentado, logicamente consistente, fundado em conhecimento de causa, tipicamente reconstrutivo" (DEMO, 1995, p. 25). Assim, as verdades passam a ser apenas pretensões de validade, estabelecidas como verdadeiras até o surgimento de novos argumentos mais fortes que exigem novamente contra-argumentos (HABERMAS, 1989).

Apresentamos, a seguir, uma proposta de organização da sala de aula com pesquisa que foi resultado de pesquisa em cursos de formação de professores 
de Ciências (GALIAZZI, 2000), que tem por objetivo problematizar as teorias dos participantes, favorecendo o enriquecimento dessas teorias por meio do diálogo oral e escrito com interlocutores teóricos e empíricos.

Proposta do educar pela pesquisa na formação inicial de professores

Argumentamos em favor do educar pela pesquisa como um processo de aprender que se dá em um ambiente de discussão, análise, produção de argumentos fundamentados e de validação desses argumentos. Esse processo potencializa o enriquecimento das teorias pedagógicas de professores formadores e alunos de cursos de formação de professores, porque entendemos que a construção de novos significados só pode acontecer se houver a problematização do conhecimento tácito para avançar em direção a um conhecimento mais complexo.

Propomos como modo de enriquecer essas teorias pedagógicas a investigação sobre um tema de relevância para o conhecimento profissional. A escolha do tema merece especial atenção do grupo proponente da pesquisa, pois o comprometimento do grupo em formação inicial depende muito de cada indivíduo entender-se partícipe dessa pesquisa.

A partir dessa escolha negociada coletivamente, a explicitação das idéias dos participantes torna possível sua contrastação. Nesse sentido, ressaltamos a importância da explicitação do conhecimento de todos os envolvidos e de prestar atenção e considerar esse conhecimento, para que ele, no processo de pesquisa, possa ser enriquecido. Sugerimos, pois, que o conhecimento inicial, que é sempre um conhecimento em processo, seja registrado para que o trabalho de pesquisa possa ser sistematizado a partir dele. A explicitação do conhecimento do grupo permite perceber as divergências de modos de pensar e favorece a discussão com vistas a fundamentar as teorias dos envolvidos. Essa discussão precisa ser feita de forma dialogada, com um entendimento de que não há a resposta certa e verdadeira e que todos os argumentos serão colocados em discussão.

O contraste de teorias impulsiona o trabalho para a fundamentação das idéias iniciais, que vai, em decorrência, proporcionar o fortalecimento de algumas delas em detrimento de outras. Nesse processo, o diálogo é imprescindível.

A construção de argumentos validados se faz pela análise do conhecimento inicial do grupo, com elaboração e discussão de sínteses dessas análises. A análise e construção das sínteses requerem a fundamentação pelo diálogo teórico e empírico com a realidade em estudo, o que exige a busca por fundamentação teórica e prática, que pode acontecer de diferentes modos. Exigem, no entanto, um movimento de abertura da sala de aula para ouvir, ler, interpretar, discutir o que os interlocutores práticos, que constituem a própria 
realidade pesquisada, têm a dizer. Isso envolve entrevistas com pessoas inseridas em contextos relacionados com o tema em investigação, e mesmo a experimentação dos argumentos construídos. Comporta também ler, discutir, dialogar com os teóricos que escrevem sobre o tema pesquisado. Esse conjunto de diálogos (teóricos e empíricos) precisa, então, ser articulado de modo a construir argumentos validados.

A pesquisa segue com a validação da pesquisa, que pode acontecer em aula, pela apresentação e discussão dos argumentos construídos, ou essa discussão pode ser expandida a comunidades ampliadas de argumentação como associações de bairro, publicação dos resultados em jornais, eventos científicos, semana acadêmica e outros ambientes de comunicação.

Como finalização de cada ciclo, não há de se esquecer a avaliação do processo, que permite construir um novo conhecimento profissional mais fundamentado, integrado com a prática do professor, além de estar alicerçado em teorias pedagógicas mais explícitas e assumidas. Esse ciclo de pesquisa está sistematizado na Figura 1.

Construção de conhecimento profissional pela pesquisa.

Fig. 1 - ESTRUTURA DE PROPOSTA DO EDUCAR PELA PESQUISA COM PROFESSORES SOBRE SEU CONHECIMENTO PROFISSIONAL

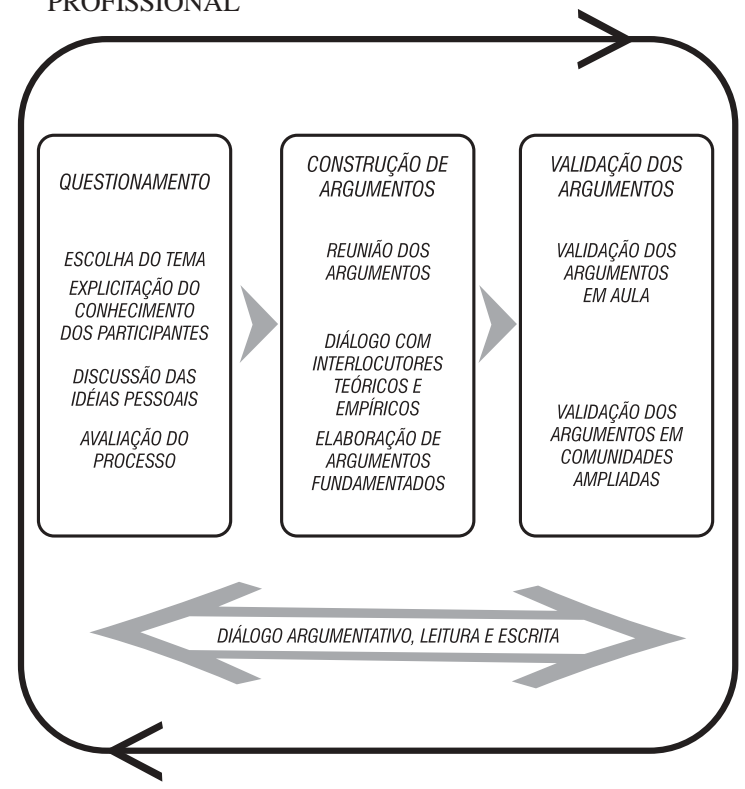


Como exemplos, relatamos brevemente algumas das pesquisas realizadas com professores formadores ou com alunos em formação. RAMOS (1999) desenvolveu com um grupo de formadores uma pesquisa coletiva que tinha como pano de fundo a avaliação dos alunos sobre seus professores. A pesquisa com esse grupo, que envolveu a análise desses dados, possibilitou a construção de entendimentos muito mais complexos sobre avaliação e outras componentes do conhecimento profissional.

A aprendizagem foi investigada por MORAES e GALIAZZI (2000) e seu grupo de alunos, a partir de relatos de alunos que haviam participado de experiências formativas em um intercâmbio da universidade com a escola. A diversidade de aprendizagens apontadas permitiu ao grupo perceber entendimentos sobre o que significa aprender. Esses entendimentos, na sua maioria, apresentavam pouca fundamentação teórica e puderam ser criticadas por meio de diálogo teórico fundamentado.

A experimentação também foi tema de uma de nossas pesquisas com alunos (GALIAZZI et al., 2001). Nessa pesquisa, um grupo de professores e alunos de um curso de Licenciatura investigou seus próprios entendimentos sobre os objetivos da experimentação no ensino médio. Os resultados produziram um conjunto de reflexões no grupo de formadores com efeitos significativos no modo de realizar as atividades experimentais em suas aulas. $\mathrm{O}$ mesmo foi feito com conteúdos específicos como metais pesados e ácidos, conteúdos de algumas de nossas disciplinas de Química na formação inicial.

Como dito anteriormente, a proposta que aqui estamos apresentando surgiu de pesquisas em cursos de formação de professores em que o educar pela pesquisa estava presente e foi investigado. Em todas as experiências analisadas, em maior ou menor grau, ocorreram resistências ao trabalho proposto. Discutimos a seguir três modos de resistências detectados naquelas aulas.

\section{As resistências em aula com pesquisa}

Parece consenso que professores têm teorias pedagógicas pessoais socialmente construídas para justificar e fundamentar sua prática em aula. Essas teorias, ao mesmo tempo que sustentam a prática, limitam avanços para perspectivas mais inovadoras de formação dos professores, justamente por terem sido construídas ao longo da vivência escolar de forma ambiental e pouco refletida. 
Com suporte teórico nas idéias de WERTSCH (1998), consideramos os limites nas teorias pedagógicas como resistências à apropriação de novos significados aos conhecimentos profissionais. Ao lembrar que esse autor considera que existe sempre uma tensão na apropriação de um novo significado por um indivíduo ou grupo, argumentamos que professores e alunos, enquanto resistem, apropriam-se, logicamente que em níveis diferenciados, dos significados do discurso que circula em aula.

Serão descritas três categorias de resistências: a inércia tradicional, a restrição ao diálogo e as teorias sobre ensino, aprendizagem e avaliação. Nenhuma dessas categorias está isolada. Elas constituem, para o professor, uma rede de significados que podem apontar para os limites do conhecimento profissional do grupo no qual ele está inexoravelmente incluído. Isso torna a superação das resistências um desafio a possibilitar a construção de teorias pedagógicas mais articuladas, fundamentadas e assumidas.

\section{Inércia tradicional}

Uma das primeiras manifestações de resistência à proposta de pesquisa em aula, em suas diferentes modalidades, acontece pela falta de esforço em entender a metodologia de trabalho. A maioria dos alunos está acostumada a uma forma conhecida e esperada de aula e tem pouco conhecimento sobre o que é fazer pesquisa. Para eles, pesquisar é fazer levantamento bibliográfico, fazer experiências no laboratório, o que não inclui leitura, fundamentação teórica, planejamento de atividades, elaboração do projeto de pesquisa. A sensação de desconforto e perplexidade dos alunos parece paradoxal, porque eles mesmos estão sempre solicitando inovação do trabalho em aula, mas à medida que a proposta ultrapassa suas teorias e expectativas com relação à disciplina, manifestam desconforto e resistência ao proposto.

A maioria dos alunos está acostumada a receber o conhecimento de forma transmissiva. Pouco lhes é exigido nas aulas tradicionais: silêncio, atenção e cópia. Esses alunos não falam o que pensam, perguntam pouco e executam, aula após aula, o que o professor planeja. De outra parte, dos alunos é exigido repetir por memorização. Esperam, pelo costume, por aulas do mesmo tipo. Como a estrutura do educar pela pesquisa é flexível, sustentada na argumentação por meio do diálogo, da leitura e da escrita, os alunos se desestabilizam com a autonomia que lhe é conferida para aprender. 
Um dos mecanismos possíveis de resistir à agenda do professor (MANKE, 1997) é dificultar o trabalho do grupo e, assim, tornar mais custoso o trabalho em aula. Essa resistência nem sempre é intencional, mas muitos alunos têm dificuldade em atender as exigências das aulas com pesquisa e uma das formas de se perceber essa resistência é a morosidade em executar as tarefas inerentes à pesquisa.

A leitura também tem sido muito pouco estimulada em aula e a inércia se manifesta pelos textos não-lidos ou lidos rapidamente, na tentativa de fazer uma síntese para cumprir a tarefa solicitada pelo professor.

Resistência maior aparece em relação à escrita, pois o aluno está acostumado à cópia. Argumentar e registrar isso está muito distante do usual na maioria das aulas e por isso os alunos resistem.

Essa forma de resistência mostra um tipo de aula conhecido, em que pouco é exigido e cujas tarefas já são de inteiro domínio de professores e alunos: explanar, copiar ou fotocopiar, transmitir e estudar dias antes da prova para memorizar e responder ao esperado. Sustentam essa expectativa a individualidade ao invés do coletivo, a passividade ao invés da autonomia.

\section{Restrição ao diálogo}

O educar pela pesquisa fundamenta-se no diálogo crítico, na linguagem e na escrita. Outra manifestação que aponta para resistências emergentes em sala de aula é a dissimetria de fala entre professores e alunos, pois esta evidencia dificuldade nos participantes em assumir teorias pedagógicas que superem entendimentos tradicionais em que o domínio da palavra é do professor. Isso é um desafio, porque os professores ainda estão muito acostumados a monopolizar a palavra em aula. As aprendizagens ambientais são muito fortes e sentir-se a autoridade, ser o que comanda ainda está muito presente em suas ações.

A dissimetria de fala também pode aparecer em razão de entendimentos dos alunos que interpretam a fala do professor como a verdade, como o ponto final da discussão. Isso mostra também teorias pedagógicas tradicionais dos alunos que não questionam o conhecimento do professor. Como a palavra do professor, em uma aula tradicional, geralmente é vista como indiscutível, a discussão dos diferentes argumentos do grupo, necessária em aula com pesquisa, 
pode confundir o aluno que espera pela resposta certa de como proceder. A convicção de inquestionabilidade à fala do professor dificulta a superação da inibição em se expor em e ao grupo. Dessa forma, os alunos resistem a falar.

Essa forma de resistência mostra entendimentos sobre a aquisição de conhecimento arraigados à transmissão de verdades inquestionáveis por um expert - o professor - a um indivíduo que desconhece o assunto - o aluno. Mostra, também, dificuldades em expressar argumento próprio e fundamentado, tendo subjacente um modelo de avaliação punitivo que sanciona o aluno que discorda e diverge do posicionamento autoritário do professor.

\section{Teorias sobre ensino, aprendizagem e avaliação}

Uma das intenções do educar pela pesquisa é superar teorias simplistas de aprendizagem, mas assumir um novo papel não é um processo espontâneo e fácil. O aluno não consegue perceber o que está aprendendo porque não recebe a exposição tradicional do conteúdo. Seu entendimento de aula prioriza a cópia e não inclui um processo de aprender a aprender. Além disso, o aluno está acostumado a aprender conceitos e fatos. Essa aprendizagem ambiental é forte, e aprender a discutir, a reescrever, a procurar bibliografia, a estruturar um projeto de pesquisa, a elaborar melhor as idéias e a argumentar, a escrever de forma mais articulada e a buscar fundamentação teórica é um processo de fácil assimilação para os alunos. Um conhecimento descrito e transmitido no quadro pode ser considerado mais produtivo em função de seus entendimentos sobre aprendizagem. Isso leva a considerar limites nos alunos em perceber a complexidade de uma proposta que tem como objetivo o desenvolvimento da capacidade de escrita, de leitura e da capacidade de argumentar, entre outros aspectos.

Da mesma forma, as teorias de ensino também limitam o enriquecimento do conhecimento profissional de professores que, mesmo privilegiando o diálogo, tem em seu posicionamento a verdade estabelecida pela ciência, ou que, ao privilegiar discussões mais amplas do que o conteúdo específico historicamente trabalhado, pontuam seus posicionamentos políticos e ideológicos como os certos.

Outro aspecto a considerar quando se pensa em aula com pesquisa é a avaliação, ponto no qual os professores e alunos mais resistem à apropriação de novos significados. Mesmo considerando que o rigor seja a essência da pesquisa e mereça atenção sempre cuidadosa, e que a importância com a qua- 
lidade do produto não pode ser desmerecida, é preciso considerar também as dificuldades dos alunos na formação inicial em executar os procedimentos inerentes à pesquisa como ler, escrever, reescrever, analisar, categorizar, fundamentar teoricamente. Assim, uma das resistências surge exatamente nos procedimentos de avaliação, em que a exigência dos professores pode ser exagerada, por um lado, e se os professores se prendem a avaliações tradicionais, os alunos, com preocupação na nota e nos requisitos necessários para a aprovação, também manifestam resistências.

Essa forma de resistência mostra teorias sobre o que significa ensinar com o fortalecimento do posicionamento do professor; sobre o que significa aprender como sendo essencialmente pela aquisição de conhecimentos conceituais estabelecidos pela ciência em detrimento de aprendizagens mais integradas que articulem conhecimentos, valores, normas e atitudes; e avaliação como produto exigido e esperado para aprovação, preferentemente na forma de graus ou conceitos.

\section{À guisa de síntese}

Propomos a inserção da pesquisa em aula como modo de transformação dos cursos de formação, da sala de aula e do conhecimento profissional dos professores. Entendemos que essa pesquisa precise explicitar as teorias pedagógicas geralmente implícitas dos envolvidos. A pesquisa, que requer coleta de dados (essas teorias seriam os dados para análise), elaboração de sínteses e reelaboração de significados, envolve a construção de conhecimento sobre o que está sendo pesquisado, o que vai permitir o enriquecimento do conhecimento profissional de cada um dos envolvidos.

Como esse processo de pesquisa em aula com professores está sustentado por teorias pedagógicas minoritárias, surge em seu desenvolvimento um conjunto de resistências que são marcas do limite do conhecimento do grupo. Entendemos a emergência das resistências como altamente positivas para o processo de enriquecimento das teorias pedagógicas pessoais, porque a emergência de uma resistência possibilita ao professor perguntar-se porque essa resistência está acontecendo.

Uma das respostas pode estar na visão dos alunos, geralmente pouco complexa, construída durante sua vivência escolar por processos minimamente 
refletidos. Isso sugere que o professor pode, pelo diálogo, contrastar essas teorias pessoais com outras mais complexas, apoiado pelas produções teóricas veiculadas em artigos, livros, internet etc. e pela análise da prática de professores. Em outro sentido, as resistências podem funcionar como um espelho para o professor, que, pela manifestação dos alunos, consegue enxergar seus limites e buscar também tornar mais complexo e enriquecido seu conhecimento profissional.

Para perceber esse movimento geralmente implícito de resistência, o professor precisa estar à escuta das manifestações de seus alunos, atento a seus silêncios e também à procura reflexiva de suas teorias pedagógicas. No entanto, o professor somente escutará, estará atento e refletirá, com a intencionalidade do desenvolvimento profissional, se desenvolver também a consciência acerca dessas resistências e de sua importância para o processo de profissionalização. Em outras palavras, seria dizer que as resistências são sinais de dissonância de teorias pessoais. Perceber esses sinais, analisá-los, refletir sobre seus possíveis significados, discuti-los, possibilita enriquecer o conhecimento profissional de todos os envolvidos, permitindo intervir de modo consciente e crítico no encaminhamento do processo de profissionalização dos futuros professores.

\section{REFERÊNCIAS}

CAÑAL, P. et al. Investigar la escuela: elementos para una ensenãnza alternativa. Sevilla: Díada, 1997.

. Investigación escolar y estrategias de enseñanza por investigación. Investigación en la Escuela, n. 38, p. 15-35, 1999.

DEMO, P. Questões para a teleducação. Petrópolis: Vozes, 1998.

. Pesquisa e construção de conhecimento: metodologia científica no caminho de Habermas. Rio de Janeiro: Tempo Brasileiro, 1997.

. Educar pela pesquisa. Campinas: Autores Associados, 1996.

. $A B C$ : iniciação à competência reconstrutiva do professor básico. Campinas: Papirus, 1995.

. Pesquisa: princípio científico e educativo. São Paulo: Cortez, 1991.

GALIAZZI, M. C. Educar pela pesquisa: espaço de transformação e avanço na for- 
mação do professor de Ciências. Porto Alegre, 2000. Tese (Doutorado em Educação) - Faculdade de Educação, Pontifícia Universidade Católica do Rio Grande do Sul.

GALIAZZI, M. C. et al. Objetivos das atividades experimentais no ensino médio: a pesquisa coletiva como modo de formação de professores de Ciências. Ciência \& Educação, v. 7, n. 2, p. 249-263, 2001.

GARCÍA, E. Hacia una teoría alternativa sobre los contenidos escolares. Sevilla: Díada, 1998.

. La naturaleza del conocimiento escolar: transición de lo cotidiano a lo científico o de lo simple a lo complejo? In: RODRIGO, M. J.; ARNAY, J. La construcción del conocimiento escolar. Barcelona: Paidós, 1997. p. 59-80.

HABERMAS, J. Consciência moral e agir comunicativo. Rio de Janeiro: Tempo Universitário, 1989.

MANKE, M. P. Classroom power relations: understanding student-teacher interaction. London: Lawrence Erlbaum Associates, 1997.

MORAES, R.; GALIAZZI, M. C. Investigando significados de um intercâmbio entre universidade e escola: olhar dos alunos da universidade. Caderno Pedagógico, n. 3, p. $65-87$, jul. 2000.

PÉREZ-GOMEZ, A. I. A função e formação do professor/a no ensino para a compreensão: diferentes perspectivas. In: SACRISTÁN, J. G.; PÉREZ-GOMEZ, A. I. Compreender e transformar o ensino. 4. ed. Tradução de: Ernani F. da Fonseca Rosa. Porto Alegre: Artmed., 1998.

PORLÁN, R.; RIVERO, A. El conocimiento de los professores. Sevilla: Díada, 1998.

RAMOS, M. G. Avaliação do desempenho docente numa perspectiva qualitativa: contribuições para o desenvolvimento profissional de professores no ensino superior. Porto Alegre, 1999. Tese (Doutorado em Educação) - Faculdade de Educação, Pontifícia Universidade Católica do Rio Grande do Sul.

SCHÖN, D. The reflective practitioner. London: Temple Smith, 1983.

WELLS, G. Dialogic inquiry: toward a sociocultural practice and theory of education. New York: Cambridge University Press, 1999.

WERTSCH, J. Mind as action. New York: Oxford University Press, 1998.

Texto recebido em 08 mai. 2002 Texto aprovado em 20 jan. 2003 